\title{
Sensor selectivity enhancement via electrochemical shielding in a recessed microelectrode array: The Gatekeeper Geometry
}

\author{
David A. Finkelstein ${ }^{*}$ \\ Institut National de la Recherche Scientifique - Énergie, Matériaux, et Télécommunications \\ (INRS-EMT), 1650 Boul. Lionel-Boulet, Varennes, Quebec, Canada J3X 1S2
}

\begin{abstract}
:
The Supporting Information includes extended Materials and Methods for both experimental and modeling results; Supporting Figures, including a demonstration of $\mathrm{O}_{2}$ interference during $\mathrm{NH}_{3}$ oxidation at $\mathrm{Pt}(100)$ films, a visualized explanation of signal amplification and shielding at a banded microelectrode array sensor, a comparison of $\mathrm{O}_{2}$ shielding between a real and modeled banded microelectrode array, and the mesh grid used for the model; and Supporting Videos showing the modeled establishment of concentration profiles and flux fields at flat and recessed microelectrode arrays, with further details included in the main text.
\end{abstract}

${ }^{*}$ Dr.David.A.Finkelstein@gmail.com 


\section{Materials and Methods}

\subsection{Reagents}

Solutions were prepared using deionized water (Millipore, $18.2 \mathrm{M} \Omega \cdot \mathrm{cm},<5 \mathrm{ppm}$ total organic content). Solutions of $0.002 \mathrm{M} \mathrm{NH}_{3}$ were prepared by dissolving $\left(\mathrm{NH}_{4}\right)_{2} \mathrm{SO}_{4}$ (Fisher, 99.5\%, trace metal grade) in $1 \mathrm{M} \mathrm{NaOH}$ (Fisher, 99\%, trace metal grade). Fresh $\mathrm{NH}_{3}$ solutions were prepared before each experiment, as the solutions were observed to decompose by $>10 \%$ over a $2 \mathrm{~h}$ period, either due to hydrolysis or reaction with ambient $\mathrm{O}_{2}$. Studies of $\mathrm{O}_{2}$ suppression were carried out in $1 \mathrm{M} \mathrm{NaOH}$ electrolyte alone and simply made use of ambient $\mathrm{O}_{2}$ dissolved into solution without agitation. All experiments were conducted at $\operatorname{STP}\left(25^{\circ} \mathrm{C}\right.$ and $\left.1 \mathrm{~atm}\right)$.

\subsection{Preparation of Pt(100) preferentially oriented thin film electrodes (Pt(100)TF):}

$\mathrm{Pt}(100) \mathrm{TF}$ electrodes were prepared via potentiostatic electrodeposition. The substrates consisted of strips of Ti foil (Alfa Aesar, 99\%, $0.2 \mathrm{~mm}$ ) masked with Teflon tape to expose square, $1 \mathrm{~cm}^{2}$ electrode areas. The substrates were pretreated according to the procedure described elsewhere. ${ }^{1}$ The deposition solution consisted of $0.5 \mathrm{mM} \mathrm{Na}_{2} \mathrm{PtCl}_{6}$. $6 \mathrm{H}_{2} \mathrm{O}$ (Alfa Aesar) in $\mathrm{pH} 2$ solution $(10 \mathrm{mM} \mathrm{HCl}$, Fisher, trace metal grade), following previously established methods. ${ }^{2}$ Depositions were carried out at $-0.24 \mathrm{~V}$ vs. $\mathrm{Ag} / \mathrm{AgCl}$ to generate a large number of $\mathrm{Pt}(100)$ terraces and step sites. ${ }^{3}$ The resulting $\mathrm{Pt}(100) \mathrm{TF}$ electrodes were then cleaned by cycling from -0.15 to $+0.6 \mathrm{~V}$ vs. $\mathrm{Ag} / \mathrm{AgCl}$ in $\mathrm{Ar}-$ purged $0.5 \mathrm{M}(1 \mathrm{~N}) \mathrm{H}_{2} \mathrm{SO}_{4}(99.5 \%$, trace metal grade). Potentials higher than $+0.80 \mathrm{~V}$ vs. $\mathrm{Ag} / \mathrm{AgCl}$ in $1 \mathrm{~N}$ acid were avoided to prevent forming Pt surface oxides that would deorient the $\mathrm{Pt}(100)$ surface. The films had an approximate roughness factor of 30 when integrating the charge in the $\mathrm{Pt}$ hydride region and assuming that one hydride monolayer had a charge of $210 \mu \mathrm{C} / \mathrm{cm}^{2}$.

\subsection{Electrochemical setup for experiments using Pt(100) films}

Electrochemical measurements were performed in a three-chambered glass cell with the counter electrode chamber separated by a medium porosity glass frit and the reference electrode $(\mathrm{Ag} / \mathrm{AgCl})$ chamber separated by a Luggin capillary. Cyclic voltammograms and chronoamperometry were performed using a Biologic VSP multipotentiostat.

\subsection{Electrochemical setup for experiments using Micrux banded microelectrode arrays}

Experiments were performed using banded, interdigitated, microelectrode arrays (Micrux IDA1) with Pt working, counter, and pseudo-reference electrodes. Each microelectrode array consisted of a total of $15 \mathrm{~W} 1$ working electrodes, each $10 \mu \mathrm{m}$ wide, $2 \mathrm{~mm}$ long, and spaced $10 \mu \mathrm{m}$ from two identical, neighboring W2 working electrodes. The Pt electrodes were $150 \mathrm{~nm}$ thick and deposited on a $50 \mathrm{~nm}$ underlayer of Ti. Electrode leads were masked by SU-8 resin, forming an exposed circular area $2 \mathrm{~mm}$ in diameter. For each experiment, a $5 \mu \mathrm{L}$ droplet was applied via micropipettor to the electrode array. Cyclic 
voltammograms and chronoamperometry were performed using a Biologic SP-300 multipotentiostat in bipotentiostat configuration.

\section{Finite Element Simulations}

\subsection{Computational Model}

Finite element simulations were performed using COMSOL Multiphysics v.4.3. A 2D cross-section of a banded interdigitated electrode array was modeled in the $x z$ plane. In the model, $x$ is the direction across the electrode surface cutting across the interdigitated bands, $y$ is the unseen direction across the electrode surface following the length of the bands, which can be extended indefinitely, and $z$ is the direction perpendicular to the $x y$ plane of the electrode surface, toward bulk solution. The model geometry is depicted in Figure 1 and described in the main text. The key geometric values are summarized in Table S1 and further model details, including duration and time step, constants, and boundary values, are summarized in Tables S2 to S4, respectivley.

The fluxes $(J)$ of $\mathrm{O}_{2}$ and $\mathrm{NH}_{3}$ to electrodes $\mathrm{W} 1$ and $\mathrm{W} 2$ and their respective concentrations $(C)$ over time $(t)$ were calculated using Fick's $1^{\text {st }}$ and 2nd Laws, respectively (Eqs. 1 and 2):

Eq.1: $J=-D\left(\frac{\partial C}{\partial x}+\frac{\partial C}{\partial z}\right)$

Eq.2: $\frac{d C}{d t}=D\left(\frac{\partial^{2} C}{\partial x^{2}}+\frac{\partial^{2} C}{\partial z^{2}}\right)$

where $D$ is the diffusion coefficient of either $\mathrm{O}_{2}$ or $\mathrm{NH}_{3}$.

The expected current $(i)$, or signal, at electrodes W1 and W2 for each species should be directly proportional to the total flux of that species to the W1 and W2 surfaces (Eq.3):

Eq.3: $i=n F A J$

where $n$ is the number of $\mathrm{e}^{-}$involved in the reaction of the species at the electrode, $F$ is Faraday's constant, and $A$ is electrode area.

For recesses of depth 25 to $100 \mu \mathrm{m}$, the models were run for $10 \mathrm{~s}$ with $0.2 \mathrm{~s}$ steps. For the depth of $200 \mu \mathrm{m}$, the model was run for $30 \mathrm{~s}$ with $0.5 \mathrm{~s}$ steps. For the depth of 400 $\mu \mathrm{m}$, the model was run for $140 \mathrm{~s}$ with $2 \mathrm{~s}$ steps (Table S2). 
At W2 shielding electrodes, the $4 \mathrm{e}^{-}$reduction of $\mathrm{O}_{2}$ was assumed (Eq.S1):

Eq.S1: $\mathrm{O}_{2}+4 \mathrm{e}^{-}+4 \mathrm{H}^{+} \rightarrow \mathrm{H}_{2} \mathrm{O}$

At W1 sensing electrodes, both the $4 \mathrm{e}^{-}$reduction of $\mathrm{O}_{2}$ (Eq. S1) and the $3 \mathrm{e}^{-}$oxidation of $\mathrm{NH}_{3}$ were assumed (Eq.S2):

Eq.S2: $\mathrm{NH}_{3} \rightarrow 1 / 2 \mathrm{~N}_{2}+3 \mathrm{e}^{-}+3 \mathrm{H}^{+}$

To simplify the model and show the highest possible benefit expected from the Gatekeeper Geometry, ideal conditions were used in which both electrochemical reactions were assumed to occur under mass-transport limited conditions at W1 and W2. These conditions also avoided errors from attempting to model $\mathrm{NH}_{3}$ oxidation, which has a complex mechanism ${ }^{4}$ that does not follow Butler-Volmer behavior.

To approximate semi-infinite linear diffusion, the model geometry accounted for $1 \mathrm{~mm}$ of distance perpendicular to the substrate/electrode surfaces ( $1 \mathrm{~mm}$ thick solution). The following values for $D$ were used: $D_{\mathrm{NH}_{3}}=1.7 \times 10^{-5} \mathrm{~cm}^{2} / \mathrm{s}$ (extrapolated from tabulated data at 15 and $20^{\circ} \mathrm{C}^{5}$ ); $D_{\mathrm{O}_{2}}=1.20 \times 10^{-5} \mathrm{~cm}^{2} / \mathrm{s}^{6}$ (Table S3). At the beginning of each modeling experiment, the concentrations of each reactant were the same throughout the solution: $C_{\mathrm{NH}_{3}}=0.3 \mathrm{mM}$ and $C_{\mathrm{O}_{2}}=0.5 \mathrm{mM}$ (see 2.3 below), with all resulting concentration gradients resulting solely from reactant consumption at the electrode surfaces (Table S4).

Electric field effects were neglected since the reactants were modeled at low concentration and high supporting electrolyte $(1 \mathrm{M} \mathrm{NaOH})$ was assumed.

\subsection{Calculations of Chemical Parameters}

The concentration of $\mathrm{NH}_{3}$ in aqueous solution $\left(C_{\mathrm{NH}_{3}}\right)$ resulting from $5 \mathrm{ppm} \mathrm{NH}$ in the sample gas was calculated using Henry's Law (Eq. S3), as appropriate for low concentration gases:

Eq. S3: $C_{\mathrm{NH}_{3}}=H_{\mathrm{NH}_{3}} P_{\mathrm{NH}_{3}}$

where $H_{\mathrm{NH}_{3}}=59 \mathrm{M} / \mathrm{atm}^{7}$ is the Henry's Law Constant for $\mathrm{NH}_{3}$ and $P_{\mathrm{NH}_{3}}$ is the partial pressure of $\mathrm{NH}_{3}$ in the sample gas.

The concentration of $\mathrm{O}_{2}$ in aqueous solution $\left(C_{\mathrm{O}_{2}}\right)$ resulting from ambient air $\left(21 \% \mathrm{O}_{2}\right)$ was calculated from tabulated values. ${ }^{5}$ 


\subsection{Finite Element Mesh}

In the finite element method, solutions for the modeling equations are solved only at specific locations in multi-dimensional space. These locations are specified using the intersections of a pre-defined mesh. Higher density meshes increase computational accuracy and detail, while lower density meshes save on the computational power.

The mesh used for the simulation of the recessed IDA with a recess depth of $50 \mu \mathrm{m}$ (Figure 1.D) is depicted in Figure S13. The mesh had a higher density closer to the electrode surface. A mesh distribution of 15 elements per $10 \mu \mathrm{m}$ was used from $x=30$ to $130 \mu \mathrm{m}, x=150$ to $240 \mu \mathrm{m}$, and $y=-50$ to $50 \mu \mathrm{m}$. A distribution of 30 elements per 10 $\mu \mathrm{m}$ was used from $x=130$ to $140 \mu \mathrm{m}$ to improve the quality of the simulations near $\mathrm{W} 1_{\mathrm{c}}$, where the concentration profiles in Figures 1.C and 1.F are shown. The mesh was less dense elsewhere in the model. A similar mesh was used for the flat IDA in Figure 1.A, where the high-density mesh of 15 elements per $10 \mu \mathrm{m}$ was used from $y=0$ to $100 \mu \mathrm{m}$. 


\section{Supporting Figures}

\begin{tabular}{cc}
\hline Dimension & Value \\
\hline Flat geometry electrode band width (W1, W2) & $10 \mu \mathrm{m}$ \\
Flat geometry interelectrode band spacing (W1 to W2) & $10 \mu \mathrm{m}$ \\
Recessed geometry, recessed electrode band width (W1) & $10 \mu \mathrm{m}$ \\
Recessed geometry, non-recessed electrode band width (W2) & $30 \mu \mathrm{m}$ \\
Recessed geometry interelectrode band spacing along x & $0 \mu \mathrm{m}$ \\
dimension (W1 to W2) & \\
Recessed geometry interelectrode band spacing along z & $50 \mu \mathrm{m}$ \\
dimension (W1 to W2) in Figures 1 and 2 & \\
Recess depth for geometry in Figures 1 and 2 & $50 \mu \mathrm{m}$ \\
Additional recess depths used in Figure 3 & $25 \mu \mathrm{m}$ \\
& $100 \mu \mathrm{m}$ \\
& $200 \mu \mathrm{m}$
\end{tabular}

Table S1: Key geometric values used in the model

\begin{tabular}{ccc}
\hline Model Parameter & Recess Depth & Value \\
\hline Simulation Duration & 0 to $100 \mu \mathrm{m}$ & $10 \mathrm{~s}$ \\
& $200 \mu \mathrm{m}$ & $30 \mathrm{~s}$ \\
& $400 \mu \mathrm{m}$ & $140 \mathrm{~s}$ \\
Time Step & 0 to $100 \mu \mathrm{m}$ & $0.2 \mathrm{~s}$ \\
& $200 \mu \mathrm{m}$ & $0.5 \mathrm{~s}$ \\
& $400 \mu \mathrm{m}$ & $2 \mathrm{~s}$
\end{tabular}

Table S2: Simulation durations and time steps for the various recess depths investigated

\begin{tabular}{ccc}
\hline Constant & Description & Value \\
\hline$D_{\mathrm{NH}_{3}}$ & Diffusion coefficient of $\mathrm{NH}_{3}$ & $1.7 \times 10^{-5} \mathrm{~cm}^{2} / \mathrm{s}$ \\
$D_{\mathrm{O}_{2}}$ & Diffusion coefficient of $\mathrm{O}_{2}$ & $1.2 \times 10^{-5} \mathrm{~cm}^{2} / \mathrm{s}$
\end{tabular}

Table S3: Constants used in the model 


\begin{tabular}{|c|c|c|}
\hline $\begin{array}{l}\text { Boundary } \\
\text { Value }\end{array}$ & Description & Value \\
\hline$C_{\mathrm{NH}_{3}, t=0}^{\mathrm{B}}$ & Bulk concentration of $\mathrm{NH}_{3}$ at $\mathrm{t}=0$ & $0.3 \mathrm{mM}$ \\
\hline$C_{\mathrm{O}_{2}, t=0}^{\mathrm{B}}$ & Bulk concentration of $\mathrm{O}_{2}$ at $\mathrm{t}=0$ & $0.5 \mathrm{mM}$ \\
\hline$C_{\mathrm{NH}_{3}}^{\mathrm{W} 1}$ & $\begin{array}{c}\text { Concentration of } \mathrm{NH}_{3} \text { at } \mathrm{W} 1 \text { surfaces throughout the } \\
\text { duration of the experiment }\end{array}$ & $0 \mathrm{mM}$ \\
\hline$C_{\mathrm{O}_{2}}^{\mathrm{W} 1, \mathrm{~W} 2}$ & $\begin{array}{c}\text { Concentration of } \mathrm{O}_{2} \text { at } \mathrm{W} 1 \text { and } \mathrm{W} 2 \text { surfaces } \\
\text { throughout the duration of the experiment }\end{array}$ & $0 \mathrm{mM}$ \\
\hline
\end{tabular}

Table S4: Boundary values used in the model 

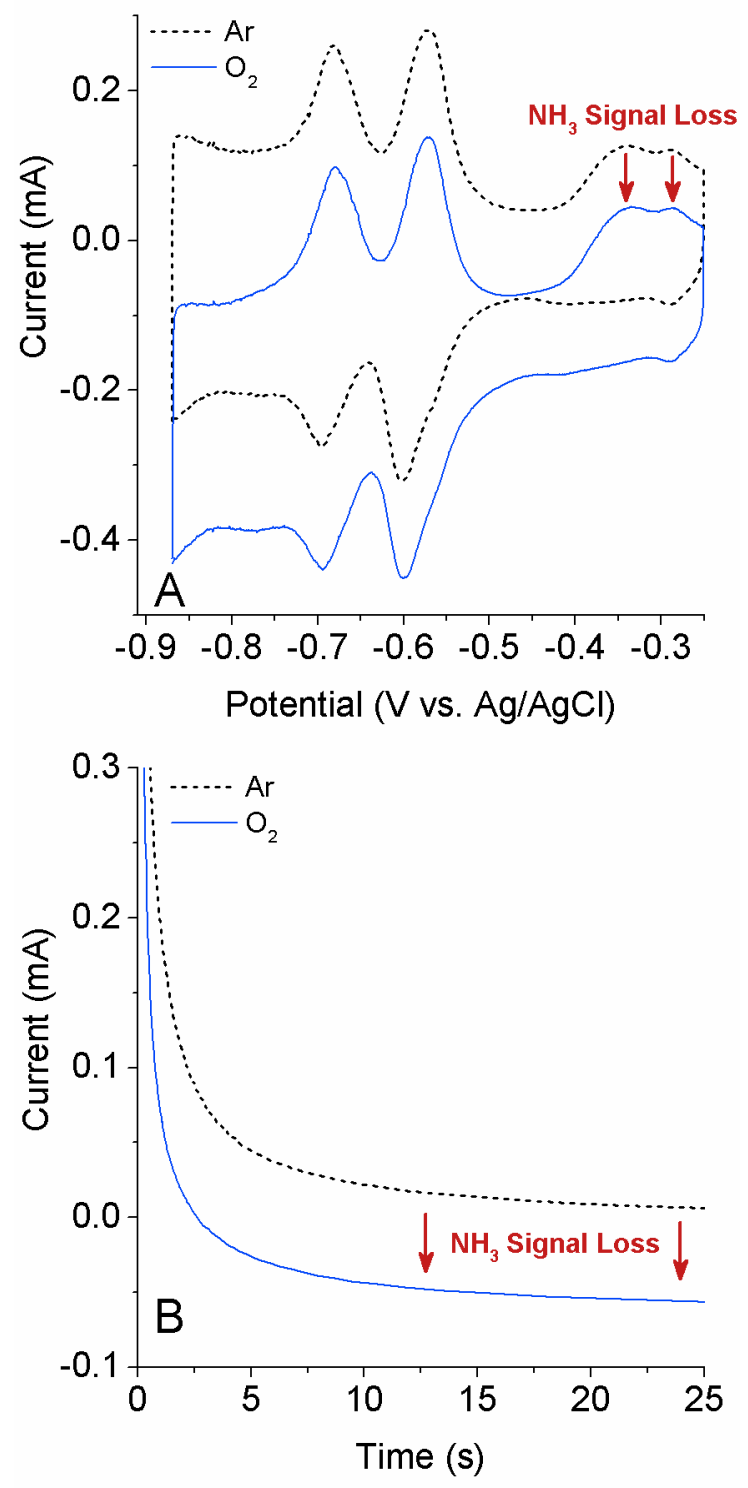

Figure S1: Effect of ambient $\mathrm{O}_{2}$ on signal from $0.2 \mathrm{mM} \mathrm{NH}_{3}(3.4 \mathrm{ppm})$ at $\mathrm{Pt}(100)$ films in $1 \mathrm{M}$ $\mathrm{NaOH}$. Cyclic voltammogram at $10 \mathrm{mV} / \mathrm{s}$ (A) and chronoamperometry at $-0.25 \mathrm{~V}$ vs. Ag/AgCl (B) of $\mathrm{NH}_{3}$ under $\mathrm{Ar}$ (dashed black line) and under ambient air (solid blue line). $\mathrm{NH}_{3}$ signal (current) appears as two peaks between -0.45 and $-0.25 \mathrm{~V}$ in the anodic sweep of (A), as highlighted by the red arrows. 


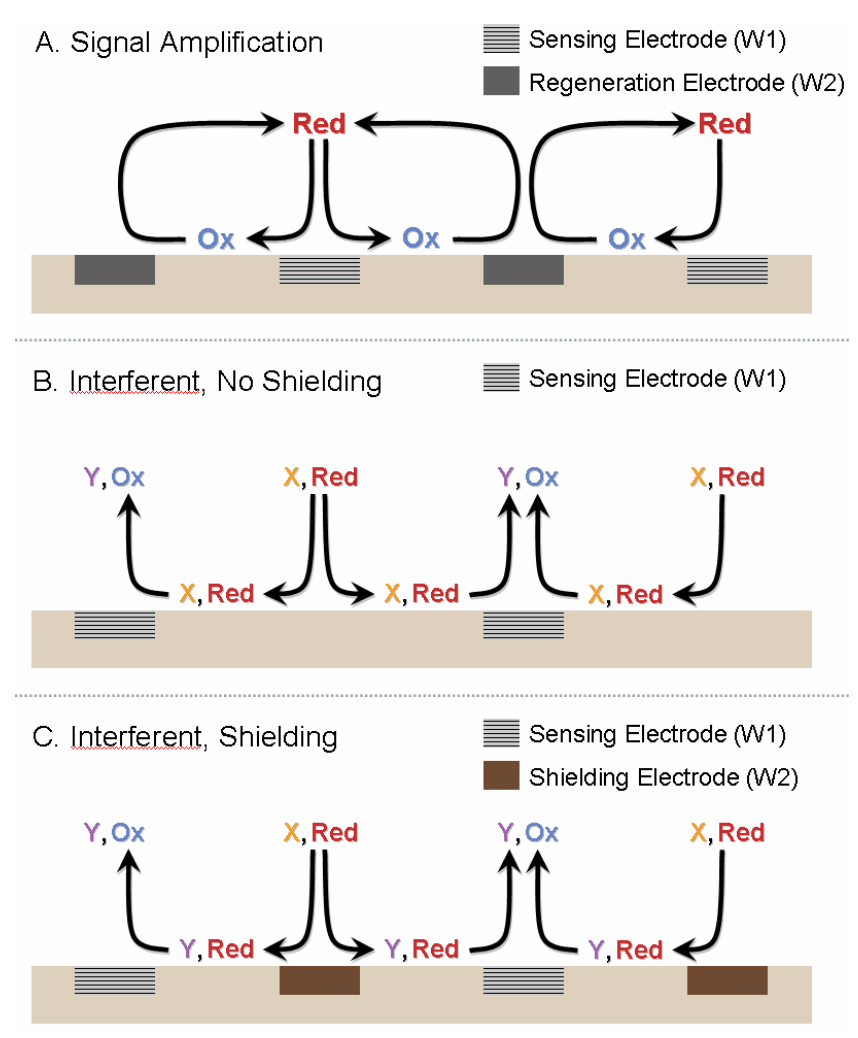

Figure S2: Illustrations of selectivity enhancement via electrochemical signal amplification (A) and shielding $(\mathrm{B}, \mathrm{C})$ for a reversible analyte that is oxidized during detection from its reduced state (Red) to its oxidized product (Ox). In signal amplification (A), Red is regenerated from Ox at the Regeneration Electrode (W2), yielding a greater local concentration of Red for enhanced signal at the Sensing Electrode (W1) relative to non-amplified interferents. When no shielding is used (B), an interferent (X) is converted to its product (Y) at the Sensing Electrode (W1) at the same potential at which Red is converted to Ox, thus producing an interfering current. When shielding is used (C), the shielding electrode (W2) selectively consumes X but not Red, preventing most $\mathrm{X}$ from reaching W1. This enhances the relative concentration, and thus signal, of Red at W1. 


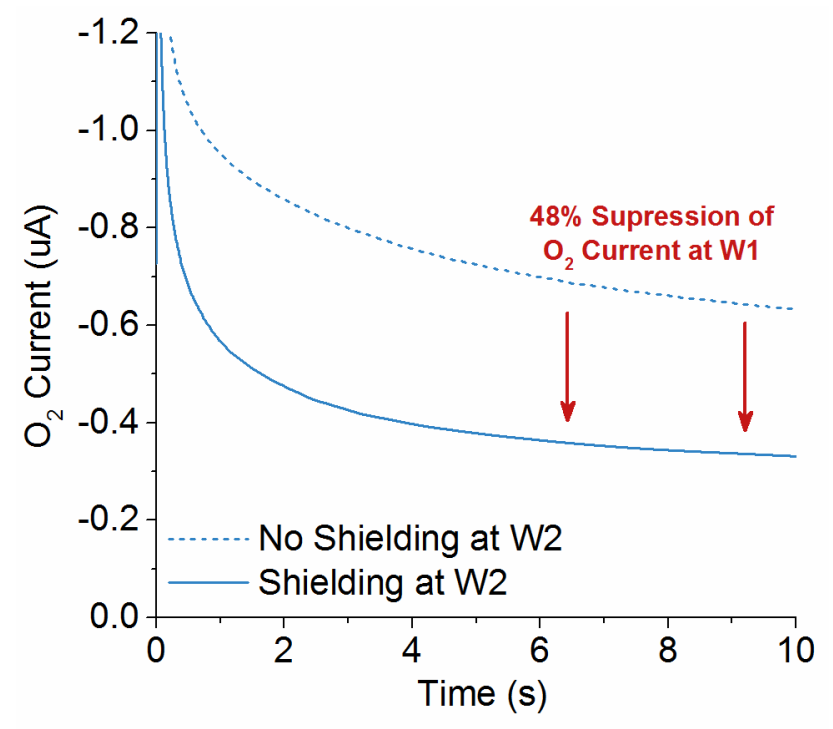

Figure S3: Shielding assessment of a commercial banded IDA (Micrux). $\mathrm{O}_{2}$ current (interferent signal) was measured at $\mathrm{W} 1$ at $-0.57 \mathrm{~V}$ vs. $\mathrm{Ag} / \mathrm{AgCl}(-0.5 \mathrm{~V}$ vs. onboard Pt pseudoreference electrode) with and without shielding of $\mathrm{O}_{2}$ current at W2 (solid and dashed blue lines, respectively).

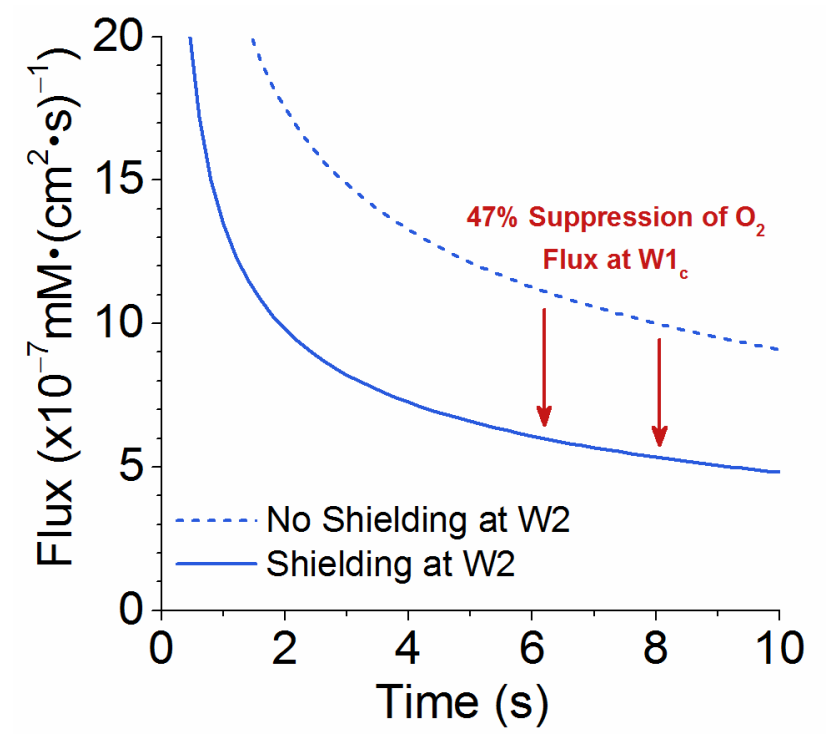

Figure S4: Shielding assessment of the simulated, flat, banded IDA in Figure $1 . \mathrm{O}_{2}$ flux to $\mathrm{W} 1_{\mathrm{c}}$ was assessed with and without shielding of $\mathrm{O}_{2}$ by W2 (solid and dashed blue lines, respectively). 


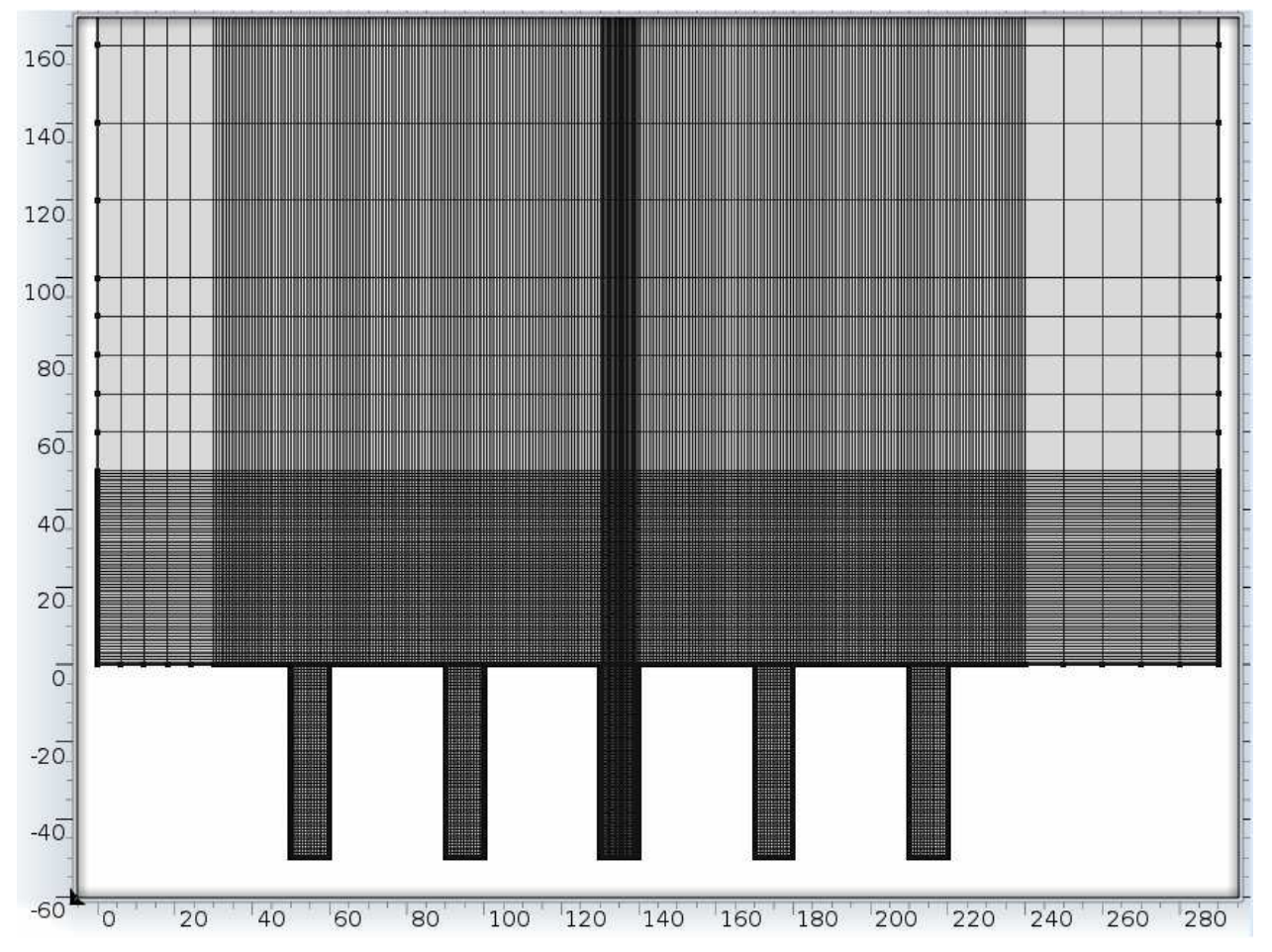

Figure S5: Mesh elements in fine element modeling of banded IDA with W1 recessed by $50 \mu \mathrm{m}$. 
Figure S6: Animation of the development of the concentration profile of $\mathrm{O}_{2}$ in the $x z$ plane above the surface of a flat IDA for $1 \mathrm{~s}$ after the application of potential to W1 and W2. The scale bar range shows $C_{\mathrm{O}_{2}}$ from 0 to $0.5 \mathrm{mM}$ (blue to red).

Figure S7: Animation of the development of the concentration profile of $\mathrm{NH}_{3}$ in the $x z$ plane above the surface of a flat IDA for $1 \mathrm{~s}$ after the application of potential to W1 and W2. The scale bar range shows $C_{\mathrm{NH}_{3}}$ from 0 to $0.3 \mathrm{mM}$ (blue to red).

Figure S8: Animation of the development of the flux profile of $\mathrm{O}_{2}$ in the $x z$ plane above the surface of a flat IDA for $1.5 \mathrm{~s}$ after the application of potential to W1 and W2. The scale bar range shows $J_{\mathrm{O}_{2}}$ from 0 to $10 \times 10^{-7} \mathrm{mmol} \cdot\left(\mathrm{cm}^{2} \cdot \mathrm{s}\right)^{-1}$ (blue to red). Regions of higher flux exceed the scale and simply appear red.

Figure S9: Animation of the development of the flux profile of $\mathrm{NH}_{3}$ in the $x z$ plane above the surface of a flat IDA for $1.5 \mathrm{~s}$ after the application of potential to $\mathrm{W} 1$ and W2. The scale bar range shows $J_{\mathrm{NH}_{3}}$ from 0 to $10 \times 10^{-7} \mathrm{mmol} \cdot\left(\mathrm{cm}^{2} \cdot \mathrm{s}\right)^{-1}$ (blue to red). Regions of higher flux exceed the scale and simply appear red.

Figure S10: Animation of the development of the concentration profile of $\mathrm{O}_{2}$ in the $x z$ plane above the surface of an IDA with W1 recessed $50 \mu \mathrm{m}$ from W2 for $1 \mathrm{~s}$ after the application of potential to $\mathrm{W} 1$ and $\mathrm{W} 2$. The scale bar range shows $C_{\mathrm{O}_{2}}$ from 0 to $0.5 \mathrm{mM}$ (blue to red).

Figure S11: Animation of the development of the concentration profile of $\mathrm{NH}_{3}$ in the $x z$ plane above the surface of an IDA with $\mathrm{W} 1$ recessed $50 \mu \mathrm{m}$ from $\mathrm{W} 2$ for $1 \mathrm{~s}$ after the application of potential to $\mathrm{W} 1$ and $\mathrm{W} 2$. The scale bar range shows $C_{\mathrm{NH}_{3}}$ from 0 to $0.3 \mathrm{mM}$ (blue to red).

Figure S12: Animation of the development of the flux profile of $\mathrm{O}_{2}$ in the $x z$ plane above the surface of an IDA with $\mathrm{W} 1$ recessed $50 \mu \mathrm{m}$ from $\mathrm{W} 2$ for $1.5 \mathrm{~s}$ after the application of potential to $\mathrm{W} 1$ and $\mathrm{W} 2$. The scale bar range shows $J_{\mathrm{O}_{2}}$ from 0 to $10 \times 10^{-7} \mathrm{mmol} \cdot\left(\mathrm{cm}^{2} \cdot \mathrm{s}\right)^{-1}$ (blue to red). Regions of higher flux exceed the scale and simply appear red.

Figure S13: Animation of the development of the flux profile of $\mathrm{NH}_{3}$ in the $x z$ plane above the surface of an IDA with $\mathrm{W} 1$ recessed $50 \mu \mathrm{m}$ from $\mathrm{W} 2$ for $1.5 \mathrm{~s}$ after the application of potential to $\mathrm{W} 1$ and W2. The scale bar range shows $J_{\mathrm{NH}_{3}}$ from 0 to $10 \times 10^{-7} \mathrm{mmol} \cdot\left(\mathrm{cm}^{2} \cdot \mathrm{s}\right)^{-1}$ (blue to red). Regions of higher flux exceed the scale and simply appear red. 


\section{Supporting Information References:}

(1) Perret, P.; Brousse, T.; Bélanger, D.; Guay, D. Electrochemical Template Synthesis of Ordered Lead Dioxide Nanowires. J. Electrochem. Soc. 2009, 156, A645-A651.

(2) Bertin, E.; Roy, C.; Garbarino, S.; Guay, D.; Solla-Gullón, J.; Vidal-Iglesias, F. J.; Feliu, J. M. Effect of the Nature of (100) Surface Sites on the Electroactivity of Macroscopic Pt Electrodes for the Electrooxidation of Ammonia. Electrochem. Commun. 2012, 22, 197199.

(3) Ponrouch, A.; Garbarino, S.; Bertin, E.; Andrei, C.; Botton, G. A.; Guay, D. Highly Porous and Preferentially Oriented 100 Platinum Nanowires and Thin Films. Adv. Funct. Mater. 2012, 22, 4172-4181.

(4) Finkelstein, D. A.; Bertin, E.; Garbarino, S.; Guay, D. Mechanistic Similarity in Catalytic $\mathrm{N}_{2}$ Production from $\mathrm{NH}_{3}$ and $\mathrm{NO}_{2}{ }^{-}$at $\mathrm{Pt}(100)$ Thin Films: Toward a Universal Catalytic Pathway for Simple N-Containing Species, and Its Application to in Situ Removal of $\mathrm{NH}_{3}$ Poisons. J. Phys. Chem. C 2015, 119 (18), 9860-9878.

(5) Lide, D. R. CRC Handbook of Chemistry and Physics; CRC Press: Boca Raton, FL, 2010.

(6) Finkelstein, D. A.; Kirtland, J. D.; Mota, N. D.; Stroock, A. D.; Abruña, H. D. Alternative Oxidants for High-Power Fuel Cells Studied by Rotating Disk Electrode (RDE)

Voltammetry at Pt, Au, and Glassy Carbon Electrodes. J. Phys. Chem. C 2011, 115, 60736084.

(7) Sander, R. Compilation of Henry's Law Constants for Inorganic and Organic Species of Potential Importance in Environmental Chemistry; http://www.henrys-law.org/henry3.0.pdf 